\title{
REVIEW
}

\section{Glycemic Control: A Combination of Lifestyle Management and the Use of Drugs}

\author{
Eberhard Standl $\cdot$ Michael Erbach • Oliver Schnell
}

To view enhanced content go to www.cardiologytherapy-open.com

Received: September 11, 2012 / Published online: November 27, 2012

(C) The Author(s) 2012. This article is published with open access at Springerlink.com

\section{ABSTRACT}

Some $30 \%$ of contemporary cardiology patients have coexisting known diabetes, and another $40 \%$ have either undiagnosed diabetes or prediabetes. There is still no final conclusive evidence of cardiovascular benefit by good glycemic control in type 2 diabetes, although studies like the United Kingdom Prospective Diabetes Study (UKPDS) and the Prospective Pioglitazone Clinical Trial in Macrovascular Events, and meta-analyses based on these and other randomized controlled trials of blood glucose-lowering therapies have been encouraging. On the other hand, microvascular disease is clearly reduced by good glycemic control. Structured education

E. Standl $(\varangle) \cdot$ M. Erbach · O. Schnell Munich Diabetes Research Group e.V., Helmholtz Centre Munich, Ingolstaedter Landstrasse 1, 85764 Munich, Neuherberg, Germany e-mail: Eberhard.Standl@lrz.uni-muenchen.de

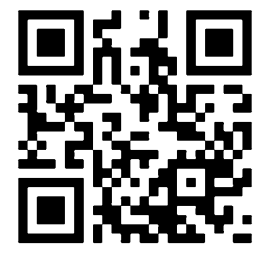

Enhanced content for this article is available on the journal web site: www.cardiologytherapy-open.com has remained a mandatory prerequisite of any successful treatment. Not only is appropriate weight management by diet and exercise able to revert new onset diabetes to normal, but it is also the foundation of any successful pharmacotherapy of diabetes. Aiming at normal fasting plasma glucose concentrations of $5.3 \mathrm{mmol} / \mathrm{L}$ or $95 \mathrm{mg} / \mathrm{dL}$ appears to be safe since publication of the long-term outcome results of the Outcome Reduction with an Initial Glargine INtervention trial. Individualized target glycosylated hemoglobin levels as near to normal as safely possible (i.e., $<7 \%$ and avoiding hypoglycaemia) are the goal for glycemic control. Hypoglycemia seems to emerge as a real concern in cardiology patients. Based on the findings of UKPDS, including the "legacy" study, metformin is the most widely recommended first-line drug therapy in type 2 diabetes, also in terms of preventing cardiovascular complications. An alternate first-line option in some parts of the world, especially Asian countries, is the class of alphaglucosidase inhibitors. In most patients, combination therapies with two or three classes of drugs are warranted. Early combination are the golden strategy as type 2 diabetes is a multi-causal disease; the various 
classes of drugs have distinct and synergistic modes of action, and the blood glucoselowering efficacy of these drugs is more or less fully maintained in combination. The recent joint American Diabetes Association/European Association for the Study of Diabetes position statement mentions five options as step two of the treatment algorithm for combination with metformin: sulfonylureas, pioglitazone, dipeptidyl peptidase-4 inhibitors, glucagon-like peptide-1 agonists, and basal insulin.

Keywords: Alpha-glucosidase inhibitors; Diet; Dipeptidyl peptidase-4 inhibitors; Exercise; Lifestyle; Sulfonylureas; Thiazolidinediones; Type 2 diabetes mellitus

\section{INTRODUCTION}

The worldwide epidemic of diabetes mellitus has also reached the field of cardiology, with some $30 \%$ of contemporary cardiology patients having coexisting known diabetes [1]. In addition, as many as $10-15 \%$ of cardiology patients have previously undiagnosed diabetes and another quarter have impaired glucose tolerance (IGT) or prediabetes, as the Euro Heart Survey and other epidemiologic evaluations have shown [1-3]. In fact, diabetes mellitus has remained to be an independent cardiovascular $(\mathrm{CV})$ risk predictor, which doubles the risk of $\mathrm{CV}$ morbidity and mortality, despite the progress made in interventional and conservative cardiology in recent years [4-6].

Glycemic control is a common challenge in cardiology patients, especially in light of the observational results obtained in the Euro Heart Survey, that early and immediate appropriate glycemic therapy appears to be of benefit in $\mathrm{CV}$ patients [7]. It should be emphasized, however, that although improved glycemic control seems to be very important to reduce the microvascular complications of diabetes in the kidneys and the eyes, the current evidence is not particularly strong in that it also reduces macrovascular complications, such as $\mathrm{CV}$ events $[4,8]$. On the other hand, fears that overambitious therapy trying to reach glycemic goals in or close to the normal range may be hazardous in its own right and increased mortality has not been confirmed by the 6-year outcome results of the randomized, controlled Outcome Reduction with an Initial Glargine INtervention (ORIGIN) trial released in June 2012 [9]. Nevertheless, hypoglycemia as a complication of blood glucose-lowering therapy has emerged to be associated with increased $\mathrm{CV}$ mortality, not necessarily as a causative factor, but rather as a surrogate of increased CV risk.

In aggregate, glycemic control is a common problem in cardiology patients that not only affords a lot of medical expertise, but also complex resources, since it can only be dealt with by intensive lifestyle management, medical education, and training. The present paper attempts, based on current guidelines [8, 10-12], to give some guidance for cardiologists to integrate care for coexisting diabetes in their patients and, hence, to summarize key aspects in achieving appropriate glycemic control in these patients.

\section{METHODS}

Up to November 2012, all published CV outcome studies evaluating available blood glucose-lowering therapies in patients with type 2 diabetes in randomized controlled trials, apart from studies in critically ill patients, were included in this review and discussed in the context of current guidelines [8, 10-12]. 


\section{STRUCTURED EDUCATION}

Diabetes may affect all aspects of daily life. Structured education, therefore, is a mandatory prerequisite of any successful treatment $[8,10$ 12] (Fig. 1). This is best achieved by a diabetes team where the physician is the director of all diagnostic and therapeutic measures, but trained and certified diabetes nurses and educators are in charge of the structured education approach. Subjects to be covered are pathogenesis of diabetes; blood glucose monitoring; nutrition; physical activity and healthy lifestyle; diabetes drugs, including the appropriate administration; hypoglycemia and its prevention; early diagnosis of microvascular, neuropathic, and macrovascular complications of diabetes and their prevention; and a wide spectrum of psychosocial issues and quality of life. Skills to be trained include blood glucose monitoring; managing the daily meal plan; insulin application if warranted; foot care; and body hygiene.
Adequate information, education, and training of patients with diabetes are principally a lifelong task. For a start, an interactive group approach based on diabetes classes, which is quality certified on a regular basis and lead by the already mentioned diabetes educators or nurses, has turned out to be the most effective and resource-saving strategy. The earlier the structured education is started, the better the lifelong success for the patient. If the care-providing institution is not equipped with the necessary resources to perform the complex education process on its own (e.g., upon the diagnosis of new diabetes), the opportunity for education and training should be provided in cooperation with specialized diabetes care centres. More individualized refresher courses may be warranted in case of hypoglycemia or if dietary failure becomes a problem. Evaluation of home glucose measurements, however, in conjunction with the attained concurrent glycosylated hemoglobin $\left(\mathrm{HbA}_{1 \mathrm{c}}\right)$ value, the

\section{- Structured education}

- Blood glucose self-monitoring (also post-prandial glucose)

- Appropriate nutrition counselling

- Pharmacotherapy discussing pros and cons

\begin{tabular}{|l|c|l|}
\hline & CV Benefits & Caveats \\
\hline Insulin & Yes & Hypoglycemia, heart? \\
\hline Metformin & Yes & $\begin{array}{l}\text { Impaired kidney function, contrast media, } \\
\text { potential hypoxemia }\end{array}$ \\
\hline Sulfonylureas & Yes & Hypoglycemia, cardiac K-channels? \\
\hline a-glucosidase-inhibitors & Yes & \\
\hline Glitazones & Yes/rosi? & CHF (CHD rosiglitazone?) \\
\hline Glinides & $?$ & Hepatic interference with other drugs (repaglinide) \\
\hline Incretin-based agents & $?$ & \\
\hline
\end{tabular}

Fig. 1 Management of patients with type 2 diabetes: cardiovascular (CV) considerations. $C H D$ coronary heart disease, $C H F$ congestive heart failure 
search for intermittent hypoglycemia, and questions regarding the daily lifestyle pattern are within the responsibility of every physician providing care for patients with diabetes at every visit to the clinic.

\section{HEALTHY LIFESTYLE: A POWERFUL TREATMENT TOOL}

Not only is appropriate weight management by diet and exercise highly effective to prevent the development of type 2 diabetes at the level of IGT, but it is also the foundation of every successful therapy for diabetes [13-15] (Fig. 1). One of the striking successes in the United Kingdom Prospective Diabetes Study (UKPDS) was the achievement of an initial mean weight loss of approximately $4 \mathrm{~kg}$ for the whole group, which transformed into a decrease of $\mathrm{HbA}_{1 \mathrm{c}}$ from approximately $9 \%$ to $7 \%$ after 3 months [16]. A stringent $600 \mathrm{kcal} /$ day diet is able to "cure" new onset type 2 diabetes [17]. A nearly immediate normalization of fasting plasma glucose (FPG) in most cases is followed by a decrease of both hepatic and pancreatic fat content, along with a restoration of insulin secretion and a normalization of $\mathrm{HbA}_{1 \mathrm{c}}$ [17]. Results like this underline the importance of ectopic fat disposition, e.g., in the liver and the pancreas (but also in the heart and muscle), as a precipitating factor for the manifestation of type 2 diabetes, which certainly has a strong and complex genetic background. An easy surrogate measure of ectopic fat is waist circumference. As a goal, waist circumference should be $<94 \mathrm{~cm}$ (37 in.) in men ( $<90 \mathrm{~cm}=35.4$ in. in Asian men) and $<80 \mathrm{~cm}$ (31.5 in.) in women [18].

The long-term randomized controlled Action for Health in Diabetes (LOOK AHEAD) study in type 2 diabetic patients has proven the principal benefits of intensive lifestyle management, including regular physical activity, on metabolic control at its 1-year and 4-year follow-up $[19,20]$, but presented some mixed results in terms of $\mathrm{CV}$ outcomes at the end of the study [21]; an average initial weight loss of $8.6 \%$ was followed by a significant decrease in $\mathrm{HbA}_{1 \mathrm{c}}$ and a reduced use of blood glucose-lowering drugs as compared to the "regular educational support and care" group. At the same time, a significant positive effect on blood pressure and lipid control, though not specifically on low-density lipoprotein (LDL)cholesterol, was seen in the intensive group, necessitating a more intense polypharmacotherapy in the standard group. Although a slight rebound phenomenon was observed after 4 years, the principle advantages of intensive lifestyle management in terms of weight loss and physical fitness were maintained; thus, demonstrating the potential of long-term efficacy on metabolic control. Despite a continued weight reduction of 5\% over an 11-year follow-up, the LOOK AHEAD study was halted due to futility to reduce prespecified CV outcomes, i.e., lower body weight and increased physical fitness in the intensive lifestyle management group did not materialize into a reduced rate of long-term $\mathrm{CV}$ complications in the context of this study, perhaps against the background of a much more intense drug therapy of $\mathrm{CV}$ risk factors in the "standard" group [21]. On the other hand, no harm was observed with intensive lifestyle management and the detailed results at termination are yet to be published.

The contribution of regular physical activity to successful lifestyle management and good metabolic control is often underestimated. Even modest activities seem to be helpful. Regular walking, i.e., more than $4 \mathrm{~h}$ a week (although preferably $5.5 \mathrm{~h}$ ) is markedly effective to reduce $\mathrm{HbA}_{1 \mathrm{c}}$, blood pressure, and blood lipids, and body weight in the long term [22]. 
For the time being, appropriate lifestyle management in type 2 diabetic patients has a strong evidence class I, level A recommendation in most guidelines [8, 10-12, 23].

\section{TREATMENT TARGETS}

The debate over the appropriate glycemic targets and whether aiming at too low $\mathrm{HbA}_{1 \mathrm{c}}$ levels (i.e., $<6.5 \%$ or even $6.0 \%$ ) may be hazardous has markedly settled down since the publication of the ORIGIN trial [9]. In this randomized, controlled, and prospective study in a total of 12,537 type 2 diabetic patients with high CV risk, including 760 patients with new screen-detected diabetes and 1,452 subjects with IGT/impaired fasting glucose, fasting normoglycemia $(<5.3 \mathrm{mM}$ or $95 \mathrm{mg} / \mathrm{dL}$ FPG) was targeted with long-acting insulin glargine in the intensive arm and compared to a more conservative approach using metformin and/or sulfonylureas as deemed necessary in the control arm. Mean FPG levels below this threshold were attained long term (median follow-up 6.2 years) in the glargine group together with very slowly rising $\mathrm{HbA}_{1 \mathrm{c}}$ levels from $5.9 \%$ at 1 year to $6.2 \%$ at 7 years. $\mathrm{HbA}_{1 \mathrm{c}}$ concentrations ranged within or very close to the normal range with glargine insulin therapy, whereas in the control group mean $\mathrm{HbA}_{1 \mathrm{c}}$ was $6.5 \%$ and mean FPG was $6.8 \mathrm{mmol} / \mathrm{L}$ or $123 \mathrm{mg} /$ dL [9]. Importantly, no negative outcomes of this intensive normalization approach were detectable, neither in terms of a composite primary outcome consisting of $\mathrm{CV}$ death and nonfatal myocardial infarction or stroke, nor in terms of the single components thereof. Furthermore, no negative outcomes were detected in terms of an extended secondary $\mathrm{CV}$ outcome, including hospitalizations for heart failure or revascularizations, nor in terms of overall mortality, and cancer development and death [9]. In addition, the large subgroup of $60 \%$ of the population in ORIGIN with preexisting $\mathrm{CV}$ events showed similar results to the total population. This suggests that targeting normoglycemia is safe, provided the rate of severe hypoglycemic episodes is as low as in ORIGIN, i.e., at about 1.0 per 100 patient years [9]. On the other hand, no discernable reduction of hard $\mathrm{CV}$ outcomes was seen over the observation period of 6.2 years, along with the rather small difference of $\mathrm{HbA}_{1 \mathrm{c}}$ of $0.3 \%$ between the two treatment groups [9].

Earlier than the ORIGIN trial, the active arm of the Action to Control Cardiovascular Risk in Diabetes study (ACCORD; 10,251 type 2 diabetic patients with mean diabetes duration of approximately 10 years at baseline), aiming at a $\mathrm{HbA}_{1 \mathrm{c}}$ level $\leq 6 \%$, was stopped prematurely because of a $30 \%$ increased risk of total and CV mortality. The reasons for this observation, however, have remained not fully elucidated, although a fourfold higher rate of severe hypoglycemia compared to the ORIGIN trial; was apparent together with a marked average weight gain of $>3 \mathrm{~kg}$ [24]. Furthermore, raising $\mathrm{HbA}_{1 \mathrm{c}}$ deliberately to a mean of $7.2 \%$ did not abolish the excessive mortality over the next 18 months, which excludes too low levels of $\mathrm{HbA}_{1 \mathrm{c}}$ as a cause of mortality. Also, the excessive mortality was exhibited in those failing to reach a primary $\mathrm{HbA}_{1 \mathrm{c}}$ target of $\leq 6.0 \%$ in the ACCORD study and struggling with a rather aggressive escalation of blood glucose-lowering therapy at $\mathrm{HbA}_{1 \mathrm{c}}$ levels of 8 and $9 \%$, whereas those achieving a goal of approximately $6.0 \% \mathrm{HbA}_{1 \mathrm{c}}$ actually benefited from the glycemic normalization approach. Most patients failing glycemic targets in the intensive arm of the ACCORD study were on a fivefold blood glucose-lowering therapy with a long-acting sulfonylurea, rosiglitazone, metformin, long-acting insulin, and multiple doses of short-acting insulin, so that potential 
adverse interactions of drugs might be a possible explanation for the study results [24].

Most importantly, this excessive mortality was not confirmed in other large scale, randomized, prospective intervention trials aiming at lower $\mathrm{HbA}_{1 \mathrm{c}}$ levels done in parallel to the ACCORD study, such as the Action in Diabetes and Vascular Disease: Preterax and Diamicron Modified Release Controlled Evaluation trial (ADVANCE; 11,140 patients with type 2 diabetes and mean diabetes duration of 8 years, aiming at a $\mathrm{HbA}_{1 \mathrm{c}}$ level $\leq 6.5 \%$ in the intensive arm) [25] and the Veterans Affairs Diabetes Trial (VADT; 1,791 type 2 diabetic patients with mean diabetes duration of 11.5 years, aiming at a $\mathrm{HbA}_{1 \mathrm{c}}$ level $\leq 6.0 \%$ in the intensive arm) [26]. In fact, several meta-analyses which included ACCORD, ADVANCE, VADT, and UKPDS, clearly showed significant benefits of targeting lower $\mathrm{HbA}_{1 \mathrm{c}}$ levels for nonfatal myocardial infarction and total coronary heart disease events [16, 24-28]. On the other hand, hypoglycemia was again a predictor of $\mathrm{CV}$ mortality in these studies, confirming the findings in the ACCORD study [24]. Extending the new learnings about hypoglycemia, it has turned out to be a myth that higher HbA1c values are protective against hypoglycemia and the associated $\mathrm{CV}$ risks in insulin treated patients. On the contrary and counterintuitively, patients on insulin therapy with higher $\mathrm{HbA}_{1 \mathrm{c}}$ levels may exhibit hypoglycemia more often than patients on insulin therapy with close to normal $\mathrm{HbA}_{1 \mathrm{c}}$ values, as first observed in the UKPDS study [16]. In addition, when hypoglycemia occurs in insulinized patients at higher $\mathrm{HbA}_{1 \mathrm{c}}$ levels it may be more deleterious in terms of $\mathrm{CV}$ fatalities [29].

Target $\mathrm{HbA}_{1 \mathrm{c}}$ levels as near to normal, i.e., $<7 \%$, yet as safe as possible (so, avoiding hypoglycemia and weight gain) are the goal for glycemic control of patients with diabetes. This requires target ranges of plasma glucose approximately $90-100 \mathrm{mg} / \mathrm{dL}(5.0-5.5 \mathrm{mmol} / \mathrm{L})$ in the fasting and pre-meal state, and $<180 \mathrm{mg} /$ $\mathrm{dL}(10 \mathrm{mmol} / \mathrm{L})$ postprandially (Fig. 1$)$. Good glycemic control, however, has to be embedded into appropriate multifactorial therapy, not only targeting good glycemic control, but also control of blood pressure, blood lipids, and other comorbidities. This approach has been adopted as the golden treatment paradigm for patients with type 2 diabetes, based on the results of the Steno-2 study, which effectively reduced both microvascular and neuropathic short-term complications, i.e., within 4 years, and macrovascular morbidity and longer-term mortality, i.e., after 8 and 13 years [30].

Last, but not least, it is clear from the discussion over the appropriate treatment target that individualization is warranted in terms of treatment targets and therapy. "One size does not fit all" and a patient-centred approach has to consider the patient's attitude towards diabetes, biological age, comorbidities, prior problems with hypoglycemia and weight gain, short or long duration of diabetes, and availability of resources. The recent joint position statement of the American Diabetes Association (ADA) and the European Association for the Study of Diabetes (EASD) has reemphasized this as the core strategy for the treatment of type 2 diabetes [10].

\section{ALGORITHM OF PHARMACOTHERAPY}

\section{Metformin}

Based on the findings of the UKPDS study, including the "legacy" study [31], metformin is 
- additive efficacy through different mode of actions

- therapy of different abnormalities

- at medium dose $70-80 \%$ of maximum effect $\rightarrow$ less side effects

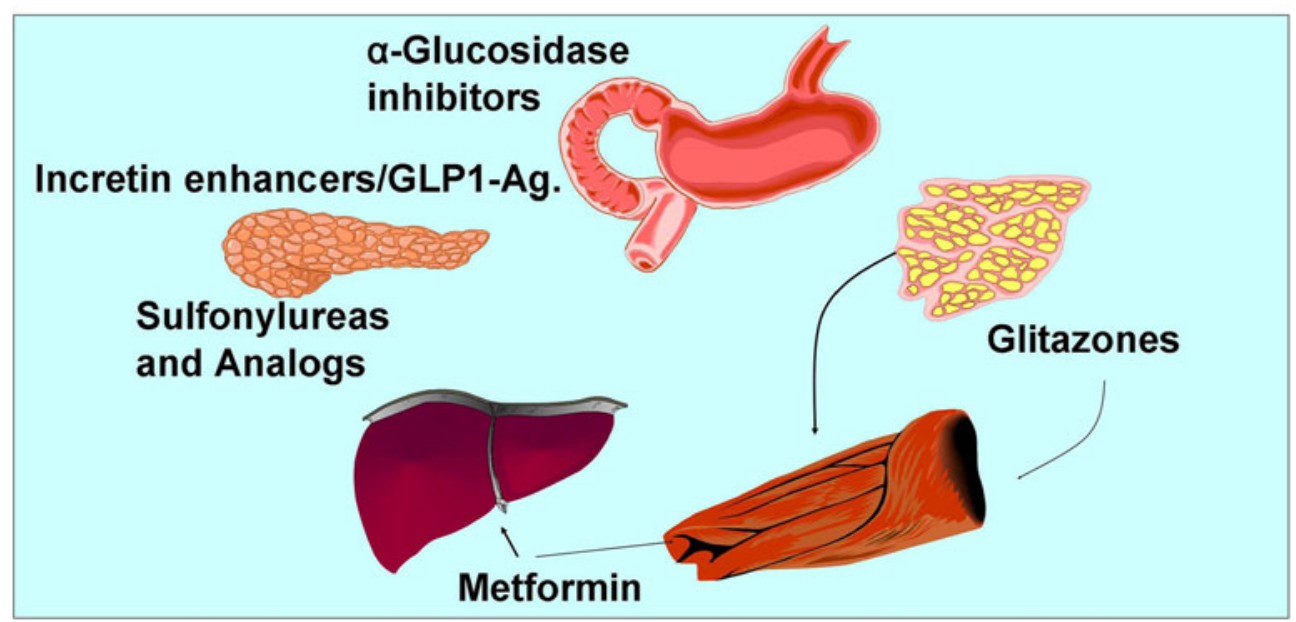

Fig. 2 Arguments in favor of early combination therapy. GLPI-Ag glucagon-like peptide-1 agonists

the most widely recommended first-line drug therapy in type 2 diabetes. It should be emphasized, however, that although the metformin UKPDS subgroup study looked encouraging, the results on reducing hard $\mathrm{CV}$ outcomes, including mortality, have never been confirmed in independent randomized trials, but only in huge observational data bases [27, 29]. Metformin has a complex mode of action, largely reducing hepatic glucose output (Fig. 2) and is especially potent in lowering FPG [32]. Metformin is efficacious, i.e., lowered $\mathrm{HbA}_{1 \mathrm{c}}$ by $1.0-1.5 \%$ in randomized controlled trials [33], causes few hypoglycemic and weight gain adverse effects, but may cause some unpleasant gastrointestinal side effects. Furthermore, the treatment costs are low as the drug has been available for $>50$ years and many generic brands are also on the market. The most significant limitation is renal insufficiency (serum creatinine $>1.5 \mathrm{mg} / \mathrm{dL}$, Fig. 1). In addition, it is important for the cardiologist to withhold the drug 1 day before angiographic examinations, other imaging procedures using contrast media, any surgery, or disease conditions with hypoxemia. With these contraindications assured, there is virtually no risk of lactic acidosis as evidenced in recent Cochrane reviews [34]. Metformin can also be used safely in patients with microalbuminurea or heart failure New York Heart Association (NYHA) classes I and II [35]. Most importantly, metformin remains the preferred partner in all potential combination therapies, including with insulin [10]. In light of this, a wide array of fixed-dose combinations of metformin with other glucose-lowering drugs are available on the market, e.g., with sulfonylureas, pioglitazone, and dipeptidyl peptidase-4 (DPP-4) inhibitors. A somewhat unsettled issue is whether metformin therapy should be implemented together with healthy life style management as soon as the diagnosis of diabetes has been made or only after a 
3-month period of exclusive lifestyle management, such as in the UKPDS study [16], which demonstrates the effectiveness of nonpharmacotherapy to the patient. This may be, however, an individual decision based on the condition of the patient and the degree of baseline metabolic derangement.

\section{Alpha-Glucosidase Inhibitors}

An alternate first-line option in some parts of the world, especially Asian countries, is the class of alpha-glucosidase inhibitors, e.g., the alphaglucosidase inhibitor, acarbose, is the most widely used oral blood glucose-lowering drug in China. Alpha-glucosidase inhibitors slow the digestion of disaccharides and more complex carbohydrates in the gut, and mainly decrease postprandial glucose levels [36] (Fig. 2). The $\mathrm{HbA}_{1 \mathrm{c}}$-lowering capacity amounts to approximately $0.8 \% \mathrm{HbA}_{1 \mathrm{c}}$ [37]. Problems with hypoglycemia or weight gain are absent with the use of these compounds. In fact, weight loss of approximately $1 \mathrm{~kg}$ is usually observed. As with metformin, some gastrointestinal side effects may occur, which require a "start low, go slow" dosage approach, and the costs are reasonable in view of generic availability. As with metformin, alpha-glucosidase inhibitors may be combined with all other treatment options, including insulin; combination with insulin seems to be helpful to prevent the weight gain usually seen with new implementation of insulin therapy [38]. Based on post hoc analysis of randomized controlled trials, alpha-glucosidase inhibitors appear to have a potential to also reduce $\mathrm{CV}$ disease [39]. Beyond the beneficial effects on postprandial hyperglycemia and weight, alphaglucosidase inhibitors also seem to have a favorable effect on dyslipidemia, blood pressure, and the retardation of new hypertension [39]. This potential to reduce CV events is currently being further explored in the randomized controlled Acarbose Cardiovascular Evaluation trial in China [40].

\section{Combination Therapies}

In most patients, combination therapies with two or three classes of drugs are warranted to achieve the intended individualized glycemic control [8, 10, 32] (Fig. 2). The choice of drugs depends largely on the individual, including stage and duration of diabetes, problems with hypoglycemia and weight gain, comorbidities, fasting hyperglycemia versus postprandial hyperglycemia, insulin resistance versus insulin deficiency, and the patient's preference are key parameters for the decision (Fig. 3) [10].

Early combination seems to be the golden strategy as type 2 diabetes is a multi-causal disease; the various classes of drugs have distinct and synergistic modes of action, and the blood glucose-lowering efficacy of these drugs is more or less fully maintained in combination. Furthermore, most blood glucose lowering drugs provide $70-80 \%$ of the maximum effect even at a medium dose, so an early combination approach is an elegant strategy to minimize side effects and to maximize efficacy (Fig. 2).

The recent joint ADA/EASD position statement [10] mentions five options as step two of the treatment algorithm for combination with metformin: sulfonylureas, pioglitazone, DPP-4 inhibitors, glucagon-like peptide-1 (GLP-1) agonists, and basal insulin (Fig. 3).

Sulfonylureas have been a cornerstone of the therapy in the UKPDS study and the ADVANCE trial $[16,25]$. They stimulate insulin secretion; however, their use is burdened by weight gain and hypoglycemia, and the durability of efficacy seems to be less sustainable compared 


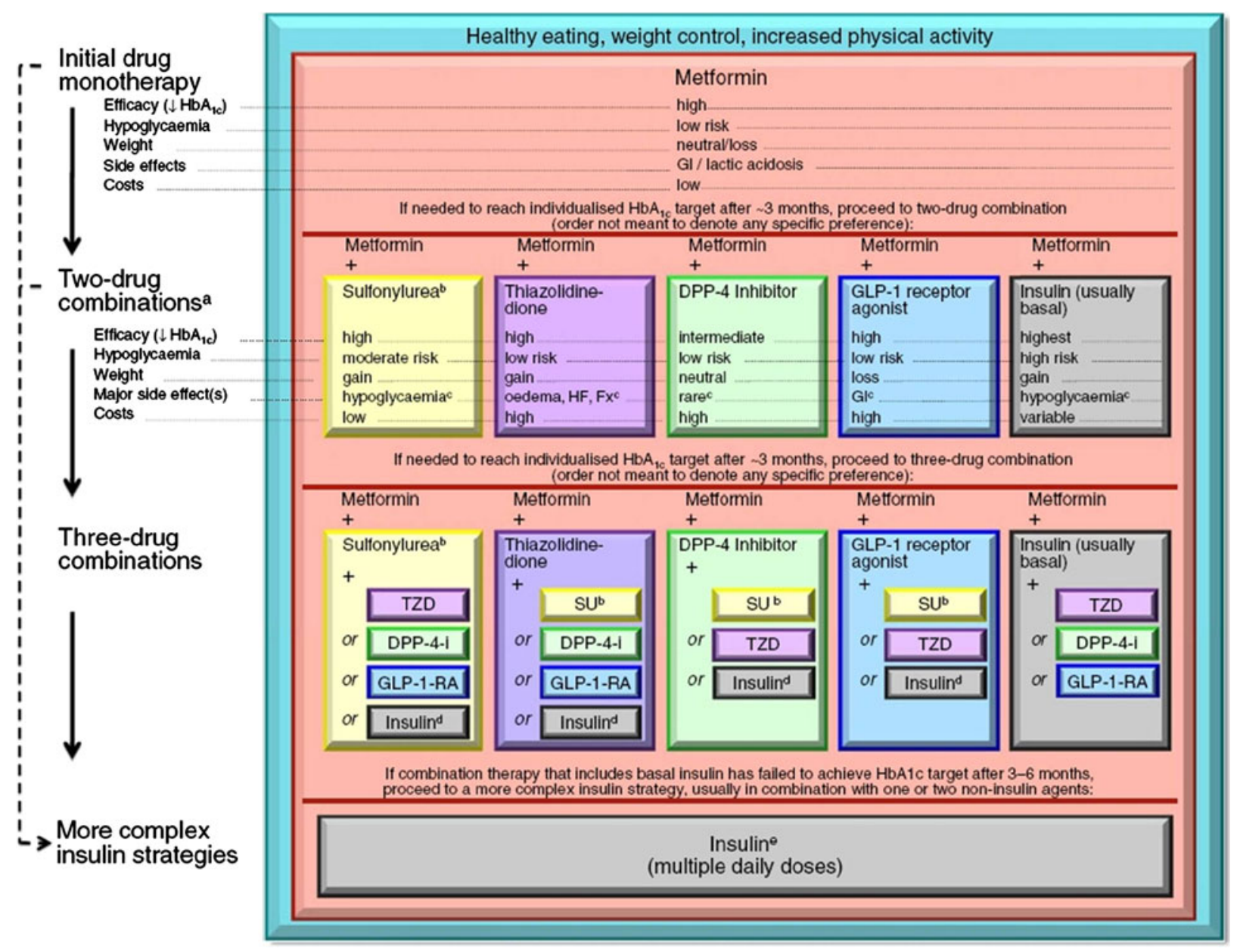

Fig. 3 EASD/ADA position statement 2012: lifestyle plus initial drug mono and combination therapy. Reproduced with permission from [10]. ADA American Diabetes Association, DPP-4 dipeptidyl peptidase-4, EASD European Association for the Study of Diabetes, GI gastrointestinal, GLP-1 glucagon-like peptide-1, GLP-1-RA glucagon-like peptide-1 receptor agonists, $H b A_{\text {Ic }}$ glycosylated hemoglobin, $S U$ sulfonylurea, $T Z D$ thiazolidinedione. ${ }^{a}$ Consider beginning at this stage in patients with very high $\mathrm{HbA}_{1 \mathrm{c}}$ (e.g., $\left.\geq 9 \%[\geq 75 \mathrm{mmol} / \mathrm{mol}]\right) .{ }^{\mathrm{b}}$ Consider rapid acting, nonsulfonylurea secretagogs (meglitinides) in patients with irregular meal schedules or who develop late postprandial hypoglycemia on sulfonylureas. ${ }^{c}$ See text box 'Properties of currently available glucose-lowering agents that may guide treatment choice in individual patients with type 2 diabetes mellitus' [10]. 'Usually a basal insulin (neutral protamine hagedorn, glargine, detemir) in combination with noninsulin agents. ${ }^{e}$ Certain noninsulin agents may be continued with insulin to metformin or thiazolidindiones (TZD) (A Diabetes Outcome Progression Trial [ADOPT]) [41]. On the other hand, sulfonylureas are the most affordable class of blood glucose lowering drugs, are available worldwide, and generate a $1.00-1.25 \%$ effect of lowering $\mathrm{HbA}_{1 \mathrm{c}}$ [42]. As already mentioned, they have also been used in the standard care group of the recently published ORIGIN trial, seemingly with good long-term success and without major adverse effects [9]. It is noteworthy, however, that in large, observational studies the use of 
sulfonylureas is regularly found to be associated with a poorer $\mathrm{CV}$ outcome, including mortality, in comparison to metformin [43]. In addition, evidence is emerging that not all sulfonylureas are alike in this regard; in the nationwide Danish database, the sulfonylurea, gliclazide, and the sulfonylurea analog, repaglinide, outperformed other sulfonylureas and showed no increased CV morbidity and mortality risk compared to metformin [43]. The latter drug, repaglinide, belongs to the class of glinides, which induce only a short pulse of insulin secretion (of approximately $1 \mathrm{~h}$ ), allowing a more flexible lifestyle omitting or adding meals, provided the drug is taken immediately prior to each ingested main meal. Repaglinide is also interesting in that it is largly eliminated by the liver, unlike most sulfonylureas, which are cleared via the kidneys. This allows repaglinide to be used in cases of some degree of renal impairment. On the other hand, because of the liver clearance, repaglinide has the potential to interfere with other drugs such as gemfibrozil, clarithromycin, ketoconazol, ciclosporin, monoamine oxidase (MAO) inhibitors, angiotensin-converting enzymes (ACE) inhibitors, salicylates, nonsteroidal antiinflammatory drugs (NSAIDs), and other commonly used drugs, and careful monitoring of therapy is very important.

\section{TZDs}

After the suspension of rosiglitazone due to the potential negative impact on ischemic heart disease, pioglitazone has remained the only TZD widely available. Unlike rosiglitazone, pioglitazone does not increase LDL cholesterol, but rather decreases serum triglycerides and increases high-density lipoprotein (HDL) cholesterol to some extent, and has shown encouraging $\mathrm{CV}$ outcome results in the
Prospective Pioglitazone Clinical Trial in Macrovascular Events (PROACTIVE; 5,238 high $\mathrm{CV}$ risk, type 2 diabetic patients with preexisting $\mathrm{CV}$ events). As peroxisome proliferator-activated receptor (PPAR)-gamma agonists, each TZD exhibits a unique pattern of gene activation. Pioglitazone regulates fatty acid storage; adipocyte differentiation and, via insulin sensitization, glucose metabolism (Fig. 2). In addition, pioglitazone shows numerous anti-inflammatory effects, raises adiponectin, and impacts favorably on endothelial cells. Clinically, pioglitazone predominantly reduces fasting hyperglycemia by its inhibitory effect on hepatic glucose output and also reduces hepatic triglyceride content. The $\mathrm{HbA}_{1 \mathrm{c}}$-lowering effect ranges from 1.00 to $1.25 \%$ [42]. Adverse effects include weight gain (especially of the subcutaneous compartment) of some $2-3 \mathrm{~kg}$ on average, potentially due to fluid retention, and an elevated risk of peripheral bone fractures in women. Pioglitazone is contraindicated in heart failure patients with NYHA classes II-IV. Likewise, it should not be used in patients with a history of bladder cancer, as there seems to be a slight, but significant, increased relative risk of bladder tumors of $10-20 \%$ associated with the use of pioglitazone. Pioglitazone has been prospectively evaluated in patients with type 2 diabetes in the PROACTIVE trial [44]. The majority of experts feel that this double-blind, controlled trial with a 3-year follow-up was a positive trial showing a reduction of $\mathrm{CV}$ events of some $15 \%$, although the primary composite outcome parameter, which included also lower limb revascularizations, demonstrated a nonsignificant advantageous trend associated with pioglitazone treatment. Patients with preexisting myocardial infarction or stroke clearly benefited from this therapy in the PROACTIVE trial. Recently, presentations at 
the EASD Annual Meeting in September 2012 underlined that during an observational followup of 6 years after the end of the PROACTIVE trial, there was neither an excessive rate of bladder malignancies in patients on prior pioglitazone therapy, nor did the favorable $\mathrm{CV}$ outcomes persist during the observational follow-up in the absence of continued pioglitazone treatment $[45,46]$. Furthermore, a meta-analysis of all available randomized trials comparing pioglitazone use with placebo or an active comparator in 22,718 patients with type 2 diabetes confirmed an $18 \%$ reduction of major adverse CV events (MACE) in patients on pioglitazone treatment [47].

In aggregate, the use of pioglitazone needs experienced differentiation at the level of the individual patient. On the other hand, it provides a powerful, sustainable therapy, best used in combination with metformin, alphaglucosidase inhibitors, or incretin based therapies, as these combinations minimize any problems with weight gain and maximize blood glucose-lowering capacity without the risk of hypoglycemia.

\section{DPP-4 Inhibitors}

DPP-4 inhibitors are a class of drugs whose use is on the rise $[10,23]$. They seem to be very well tolerated, yet their efficacy $\left(0.7-1.0 \% \mathrm{HbA}_{1 \mathrm{c}^{-}}\right.$ lowering capacity) appears to be somewhat less than that of metformin, pioglitazone, or sulfonylureas [48]. They increase insulin secretion (Fig. 2) and reduce inadequately high glucagon levels after a meal by their inhibitory effect on the degradation of the physiologically released incretine hormone, GLP-1, from L-cells in the small intestines. DPP-4 inhibitors are seen as weight neutral and have very little risk of hypoglycemia, in contrast to sulfonylureas. They mainly reduce postprandial hyperglycemia and are ideal partners for combination therapies, particularly with metformin (where there seems to be synergistic effects on GLP-1 levels), alphaglucosidase inhibitors, or pioglitazone. Sitagliptin is the most widely used compound of this class; its labeling also allows monotherapy and combination with insulin. All DPP-4 inhibitors (with the exception of vildagliptin) are currently evaluated in prospective, randomized, controlled trials for vascular and other outcomes, the results of which will be available from 2015/16 onwards.

\section{GLP-1 Agonists}

GLP-1 agonists are another option of incretinbased therapies [10, 23, 32]. They are a group of injectable compounds used in pharmacological doses. The molecules are derivatives of the natural incretine hormone, GLP-1, and are resistant to the physiological degradation process by the DPP-4 enzyme. They bind to the GLP-1 receptors and induce GLP-1 signaling. Beyond the already mentioned effects of stimulating insulin secretion and inhibiting glucagon release, GLP-1 agonists also inhibit appetite via complex mechanisms on the brain, and delay gastric emptying. The latter effect may generate gastrointestinal side effects, including nausea, vomiting, and, in some cases, diarrhoea. This potential warrants a "start low, go slow" therapy approach. The $\mathrm{HbA}_{1 \mathrm{c}}$-lowering capacity is superior to DPP-4 inhibitors $\left(1.0-1.5 \% \quad \mathrm{HbA}_{1 \mathrm{c}}\right)$ and therapy is usually associated with a significant weight loss of $3-5 \mathrm{~kg}$ on average [49]. Dosing and effect on the blood glucose pattern depend on the formulation. Short-acting exenatide mainly reduces postprandial hyperglycemia and requires twice-daily dosing. Longer-acting liraglutide decreases both fasting and 
postprandial hyperglycemia and is dosed once daily, whereas very long-acting exenatide is injected once a week and lowers the whole 24-h blood glucose profile. Like DPP-4 inhibitors, both available GLP-1 agonists are currently being studied in long-term randomized controlled trials looking at $\mathrm{CV}$ outcomes, addressing both the exclusion of potential $\mathrm{CV}$ harm and clear $\mathrm{CV}$ benefits. These studies are also expected to clarify the ongoing debate of whether incretin-based therapies might be associated with an increased risk of pancreatitis and even pancreatic carcinoma. Liraglutide has also raised concerns over a somewhat increased risk of medullary thyroid cancer, as seen in two animal species [50]. GLP-1 agonists can be combined with metformin or other noninsulinotropic blood glucose-lowering drugs with little risk of hypoglycemia. Combinations with DPP-4 inhibitors are not recommended, and combinations with sulfonylureas or insulin need to be monitored for the risk of hypoglycemia. GLP-1 agonists are also useful in triple combination therapies and seem to be effective to postpone the need for complex insulin therapy in type 2 diabetes long term.

\section{Long-Acting Insulin}

Long-acting insulin, typically as a long-acting insulin analog, in combination with metformin is seen as one of five options of the second step combinations in the recent joint ADA/EASD treatment algorithm for type 2 diabetes (Fig. 3) [10]. Other guidelines delay the use of insulin in general until the third step in the treatment algorithm [12]. In theory, and depending upon the insulin dose used, insulin therapy should yield nearly unlimited efficacy, were it not for the risk of hypoglycemia and weight gain. In most studies, an $\mathrm{HbA}_{1 \mathrm{c}}$-lowering capacity of $1.0-2.0 \%$ is attained. Long-acting insulin targeting fasting blood glucose was one of the key therapeutic components used in the UKPDS study and was found to be associated with significant outcome benefits, including the "legacy" effect on overall mortality and myocardial infarction $[16,31]$. The term "legacy" effect refers to the fact that a significant benefit emerged for mortality and myocardial infarction, which had not be seen in this clarity earlier, 10 years after the end of the randomized controlled trial phase of UKPDS and despite no further significant difference of $\mathrm{HbA}_{1 \mathrm{c}}$ values, compared to the less intensive treatment group [31]. Long-acting insulin was also used in the recently published ORIGIN trial [9]. Lessons from this and other trials seem to indicate very little risk of weight gain and hypoglycemia if long-acting insulin is used in the early stages of type 2 diabetes. Also, neither the debated cancer issue nor assumed increased risk of $\mathrm{CV}$ complications seems to be substantiated in association with the early use of insulin, even in patients with preexisting CV disease. On the other hand, and notwithstanding the potential of another "legacy" effect in the future, in view of the absence of a specific beneficial effect in the ORIGIN trial as compared to more conventional therapies with metformin and sulfonylureas, long-acting insulin seems to be only one option among others for second step therapy.

\section{Triple Combination Therapies}

The recent joint ADA/EASD position statement officially recognizes triple combination therapies as a useful third step in the treatment algorithm of type 2 diabetes (Fig. 3) [10]. Triple combinations are composed of the classes of drugs already discussed so far, and are 
tailored to the needs of the individual patient. They may consider the individual metabolic phenotype, avoiding hypoglycemia, weight gain, coexisting nonalcoholic fatty liver disease, and other comorbidities, as well as the patient's preferences and availabilities of resources.

In case individual treatment options are still not met despite triple combination therapies, alternate triple combinations may be tried under inclusion of injectables (GLP-1 agonists, if warranted, or long-acting insulin). In patients with a longer duration of the disease, often more complex insulin strategies may be needed as a fourth treatment step (Fig. 3). Depending on the daily blood glucose (and lifestyle) pattern, intensification of insulin therapy can be achieved by adding one or two pre-meal injections of short-acting insulin (analogs) to long-acting insulin at bedtime or before supper, by switching to twice-daily premixed insulin injections of short- and long-acting insulin before breakfast and supper, or by going to full-scale intensified insulin therapy with sufficient coverage of the 24-h basal insulin demand and short-acting insulin (analogs) before each main meal. Continuation of metformin therapy is widely recommended along with more complex insulin strategies to preserve the specific benefits of this therapy and reduce the daily insulin dose. Similarly, alphaglucosidase inhibitors have been used to minimize the weight gain issue with stepping up insulin therapy in some parts of the world. A new emerging strategy, depending on availability, seems to be the combination of long-acting insulins for coverage of the basal 24-h insulin demand and GLP-1 agonists to control the postprandial rise of blood glucose, again in conjunction with metformin.

In aggregate, a patient-centred approach is crucial for successful glycemic control. The availability of a continuously growing and enormously wide spectrum of treatment options and rather complex differentiations may look overwhelming at times. More complex therapies might warrant the cooperation with a diabetologist/ endocrinologist, and the need for education and training on the side of the patients, which usually requires a specialized centre, is required.

\section{CONCLUSION}

New classes of blood glucose-lowering drugs will shortly hit the market and increase the complexity further. A "magic bullet," however, that does it all in one is not on the horizon, and the complexity of therapy will certainly remain with us for the next decade. In view of the millions of people worldwide with undiagnosed or, if diagnosed, poorly controlled diabetes, the biggest contemporary challenge is inertia to diagnose and treat diabetes properly. The intricate, yet intense, interaction between diabetes mellitus and CV complications gives the cardiologist a unique opportunity to set the scene for appropriate diagnostic and therapeutic movements at the crossroads of metabolic and vascular diseases.

\section{ACKNOWLEDGMENTS}

This activity has been supported by an educational grant of the Association for the Support of International Scientific Communication in Diabetology e.V., Munich, Germany. Dr. Standl is the guarantor for this article, and takes responsibility for the integrity of the work as a whole.

Conflict of interest. Professor Standl is a member of the Task Force for First Joint EASD/ 
ESC Guidelines; DSMBs: PROActive, Navigator, ACE Trials; an investigator for studies initiated by Oxford Trial Unit, Bayer Schering, Menarini, Novartis, NovoNordisk, Sanofi-Aventis, Servier, MSD/Merck; and has received lecturing honoraria and consultation fees for AstraZeneca, Bayer, BMS, GSK, Johnson \& Johnson, Lilly, Menarini, Merck-Serono, MSD/ Merck, Novartis, NovoNordisk, Rambaxi, Roche, Sanofi-Aventis, Servier, and Takeda. Dr. Erbach and Dr. Schnell declare no conflict of interest.

Open Access. This article is distributed under the terms of the Creative Commons Attribution Noncommercial License which permits any noncommercial use, distribution, and reproduction in any medium, provided the original author(s) and the source are credited.

\section{REFERENCES}

1. Bartnik M, Ryden L, Ferrari R, Euro Heart Survey Investigators, et al. The prevalence of abnormal glucose regulation in patients with coronary artery disease across Europe. The Euro Heart Survey on diabetes and the heart. Eur Heart J. 2004;25:1880-90.

2. Kowalska I, Prokop J, Bachorzewska-Gajewska H, et al. Disturbances of glucose metabolism in men referred for coronary arteriography. Postload glycemia as predictor for coronary atherosclerosis. Diabetes Care. 2001;24:897-901.

3. Norhammar A, Tenerz A, Nilsson G, et al. Glucose metabolism in patients with acute myocardial infarction and no previous diagnosis of diabetes mellitus: a prospective study. Lancet. 2002;359:2140-4.

4. Schnell O, Standl E. Diabetes and cardiovascular disease. Current status of trials. Clin Res Cardiol Suppl. 2010;27-34.

5. Sarwar N, Gao P, Seshasai SR, et al. Diabetes mellitus, fasting blood glucose concentration, and risk of vascular disease: a collaborative metaanalysis of 102 prospective studies. Lancet. 2010;375:2215-22.
6. Haffner SM, Lehto S, Ronnemaa T, Pyorala K, Laakso M. Mortality from coronary heart disease in subjects with type 2 diabetes and in nondiabetic subjects with and without prior myocardial infarction. N Engl J Med. 1998;339:229-34.

7. Anselmino M, Öhrvik J, Malmberg K, Standl E, Ryden L, Euro Heart Survey Investigators. Glucose lowering treatment in patients with coronary artery disease is prognostically important not only in established but also in newly detected diabetes mellitus: a report from the Euro Heart Survey on Diabetes and the Heart. Euro Heart J. 2008;29:177-84.

8. Ryden L, Standl E, Bartnik M, et al. Guidelines on diabetes, pre-diabetes, and cardiovascular diseases: executive summary. The Task Force on Diabetes and Cardiovascular Diseases of the European Society of Cardiology (ESC) and of the European Association for the Study of Diabetes (EASD). Eur Heart J. 2007;28:88-136.

9. Gerstein HC, Bosch J, Dagenais GR, et al. Basal insulin and cardiovascular and other outcomes in dysglycemia. N Engl J Med. 2012;367:319-28.

10. Inzucchi SE, Bergenstal RM, Buse JB, American Diabetes Association, European Association for the Study of Prediabetes. Management of hyperglycaemia in type 2 diabetes: a patientcentered approach. Position statement of the American Diabetes Association (ADA) and the European Association for the Study of Diabetes (EASD). Diabetologia. 2012;55:1577-96.

11. American Diabetes Association. Standards of medical care in diabetes-2012. Diabetes Care. 2012;35(Suppl. 1):S11-63.

12. IDF. International Diabetes Federation: Global guideline for type 2 diabetes. Available at http://www.idf.org/global-guideline-type-2-diabetes2012. Accessed Oct 202012.

13. Tuomilehto J, Lindstrom J, Eriksson JG, Finnish Diabetes Prevention Study Group. Prevention of type 2 diabetes mellitus by changes in lifestyle among subjects with impaired glucose tolerance. N Engl J Med. 2001;344:1343-50.

14. Knowler WC, Barrett-Connor E, Fowler SE, et al. Diabetes Prevention Program Research Group. Reduction in the incidence of type 2 diabetes with lifestyle intervention or metformin. N Engl J Med. 2002;346:393-03.

15. Pan XR, $\mathrm{Li} \mathrm{GW}, \mathrm{Hu} \mathrm{YH}$, et al. Effects of diet and exercise in preventing NIDDM in people with impaired glucose tolerance. The Da Qing IGT and Diabetes Study. Diabetes Care. 1997;20: 537-44. 
16. United Kingdom Prospective Diabetes Study (UKPDS). 13: Relative efficacy of randomly allocated diet, sulphonylurea, insulin, or metformin in patients with newly diagnosed noninsulin dependent diabetes followed for three years. BMJ. 1995;310:83-8.

17. Lim EL, Hollingsworth KG, Aribisala BS, Chen MJ, Mathers JC, Taylor R. Reversal of type 2 diabetes: normalisation of beta cell function in association with decreased pancreas and liver triacylglycerol. Diabetologia. 2011;54:2506-14.

18. IDF. The IDF consensus worldwide definition of the Metabolic Syndrome. Available at: http://www.idf. org/webdata/docs/IDF_Meta_def_final.pdf. Accessed Aug 312012.

19. Pi-Sunyer X, Blackburn G, Brancati FL, et al. Reduction in weight and cardiovascular disease risk factors in individuals with type 2 diabetes: one-year results of the look AHEAD trial. Diabetes Care. 2007;30:1374-83.

20. Wing RR. Long-term effects of a lifestyle intervention on weight and cardiovascular risk factors in individuals with type 2 diabetes mellitus: four-year results of the Look AHEAD trial. Arch Intern Med. 2010;170:1566-75.

21. Heartwire. Look AHEAD halted: Life style management fails to reduce hard outcomes in diabetics. Available at: http://www.theheart.org/ article/1458351.do. Accessed Nov 52012.

22. Di Loreto C, Fanelli C, Lucidi P. Make your diabetic patient walk. Long term impact of different amounts of physical activity on type 2 diabetes. Diabetes Care. 2005;28:1295-302.

23. Blonde L. Improving care for patients with type 2 diabetes: applying management guidelines and algorithms, and a review of new evidence for incretin agents and lifestyle intervention. Am J Manag Care. 2012;17(Suppl. 14):S368-76.

24. Gerstein HC, Miller ME, Byington RP, et al. Effects of intensive glucose lowering in type 2 diabetes. N Engl J Med. 2008;358:2545-59.

25. Patel A, MacMahon $S$, Chalmers J, et al. Intensive blood glucose control and vascular outcomes in patients with type 2 diabetes. $\mathrm{N}$ Engl J Med. 2008;358:2560-72.

26. Duckworth W, Abraira C, Moritz T, VADT Investigators. Glucose control and vascular complications in veterans with type 2 diabetes. N Engl J Med. 2009;360:129-39.

27. Turnbull FM, Abraira C, Anderson RJ, et al. Intensive glucose control and macrovascular outcomes in type 2 diabetes mellitus. Diabetologia. 2009;52:2288-98.

28. Ray KK, Seshasai SR, Wijesuriya S, et al. Effect of intensive control of glucose on cardiovascular outcomes and death in patients with diabetes mellitus: a meta-analysis of randomized controlled trials. Lancet. 2009;373:1765-72.

29. Riddle MC, Ambrosius WT, Brillon DJ. Action to Control Cardiovascular Risk in Diabetes Investigation. Epidemiologic relationships between $\mathrm{A} 1 \mathrm{C}$ and all-cause mortality during a median 3.4-year follow-up of glycemic treatment in the ACCORD trial. Diabetes Care. 2010;33:983-90.

30. Gaede P, Lund-Andersen H, Parving HH, Pedersen O. Effect of a multifactorial intervention on mortality in type 2 diabetes. $\mathrm{N}$ Engl J Med. 2008;358:580-91.

31. Holman RR, Paul SK, Bethel MA, Matthews DR, Neil HA. 10-year follow-up of intensive glucose control in type 2 diabetes. $\mathrm{N}$ Engl J Med. 2008;359:1577-89.

32. Nathan DM, Buse JB, Davidson MB, American Diabetes Association, European Association for Study of Diabetes. Management of hyperglycaemia in type 2 diabetes: a consensus algorithm for the initiation and adjustment of therapy. A consensus statement from the American Diabetes Association and the European Association for the Study of Diabetes. Diabetologia. 2006;49:1711-21.

33. Hirst JA, Farmer AJ, Ali R, Roberts NW, Stevens RJ. Quantifying the effect of metformin treatment and dose on glycemic control. Diabetes Care. 2012;35:446-54.

34. Salpeter S, Greyber E, Pasternak G, Salpeter E. Risk of fatal and nonfatal lactic acidosis with metformin use in type 2 diabetes mellitus. Cochrane Database Syst Rev. 2006:CD002967.

35. Eurich DT, Majumdar SR, McAlister FA, Tsuyuki RT, Johnson JA. Improved clinical outcomes associated with metformin in patients with diabetes and heart failure. Diabetes Care. 2005;28:2345-51.

36. Standl E, Schnell O. Alpha-glucosidase-inhibitors 2012-cardiovascular considerations and trial evaluation. Diabetes Vasc Dis Res. 2012;9:163-9.

37. van de Laar FA, Lucassen PL, Akkermans RP, et al. Alpha-glucosidase inhibitors for patients with type 2 diabetes: results from a Cochrane systematic review and meta-analysis. Diabetes Care. $2005 ; 28: 154-63$

38. Schnell O, Mertes G, Standl E. Acarbose and metabolic control in patients with type 2 diabetes 
with newly initiated insulin therapy. Diabetes Obes Metab. 2007;9:853-8.

39. Chiasson JL, Josse RG, Gomis R, STOP-NIDDM Trial Research Group. Acarbose treatment and the risk of cardiovascular disease and hypertension in patients with impaired glucose tolerance: the STOP-NIDDM trial. JAMA. 2003;290:486-94.

40. University of Oxford. Acarbose Cardiovascular Evaluation (ACE) trial, launched 11 April 2008. Available at http://www.dtu.ox.ac.uk/ace/index. Accessed Aug 312012.

41. Kahn SE, Haffner SM, Heise MA, ADOPT Study Group. Glycemic durability of rosiglitazone, metformin, or glyburide monotherapy. N Engl J Med. 2006;355:2427-43.

42. Sherifali D, Nerenberg K, Pullenayegum E, Cheng JE, Gerstein HC. The effect of oral antidiabetic agents on A1C levels: a systematic review and metaanalysis. Diabetes Care. 2010;33:1859-64.

43. Schramm TK, Gislason GH, Vaag A, et al. Mortality and cardiovascular risk associated with different insulin secretagogues compared with metformin in type 2 diabetes, with or without previous myocardial infarction: a nationwide study. Eur Heart J. 2011;32:1900-8.

44. Dormandy JA, Charbonnel B, Eckland DJ, PROactive Investigators. Secondary prevention of macrovascular events in patients with type 2 diabetes in the PROactive Study (PROspective
pioglitAzone Clinical Trial In macroVascular Events): a randomised controlled trial. Lancet. 2005;366:1279-89.

45. Spanheimer R, Erdmann E, Song E, et al. Pioglitazone and bladder malignancy during observational follow-up of PROACTIVE: 6-year update. Diabetologia. 2012;55(Suppl. 1):S324.

46. Erdmann E, Song E, Spanheimer R, et al. Pioglitazone and macrovascular outcomes during observational follow-up of PROACTIVE: 6-year update. Diabetologia. 2012;55(Suppl. 1):S498.

47. Perez A, Song E, Edmonds A. MACE associated with pioglitazone: a meta-analysis of randomized, controlledd trials. Diabetologia. 2012;55(Suppl. 1):S499.

48. Deacon CF. Dipeptidyl peptidase-4 inhibitors in the treatment of type 2 diabetes: a comparative review. Diabetes Obes Metab. 2011;13:7-18.

49. Madsbad S, Kielgast U, Asmar M, Deacon CF, Torekov SS, Holst JJ. An overview of once-weekly GLP-1 receptor agonists-available efficacy and safety data and perspectives for the future. Diabetes Obes Metab. 2011;13:394-407.

50. Bjerre Knudsen L, Madsen LW, Andersen S, et al. Glucagon-like peptide-1 receptor agonists activate rodent thyroid C-cells causing calcitonin release and C-cell proliferation. Endocrinology. 2010;151:1473-86. 